\title{
Perceptions of South African Teachers and Students in Residential Secondary Schools for the Blind on Inclusive Education
}

\author{
Mbulaheni Obert Maguvhe (PhD) \\ Associate Professor, University of South Africa, College of education, \\ Department of Inclusive Education, University of South Africa, \\ P.O. Box 392, UNISA Pretoria 0003 \\ Email:maguvmo@unisa.ac.za
}

Doi:10.5901/mjss.2014.v5n20p1758

\begin{abstract}
This study investigated perceptions of both blind students and their teachers in residential secondary schools on inclusive education in South Africa. The study is a harbinger to several studies that seek to consult teachers of blind students and students themselves on their views regarding the importance of inclusive education. In this study, the researcher used focus groups to gather information from teachers and students. A sample of six teachers (four male and two female); and eighty-three students of whom forty-four were boys and thirty-nine were girls was used. Data was collected using semi-structured interview schedules. Data was presented in thematic sections and qualitatively examined for meaning. The study found out that students in residential secondary schools were barely aware of the inclusive drive. They had yet to see examples of their friends in inclusive schools. They agreed though that the concept of inclusive schooling was noble as it would enormously contribute in the reduction of the number of blind students who could not be admitted in existing special schools. Teachers wanted to see action beyond the policies which they were well aware of.
\end{abstract}

Keywords: Inclusive Education. Education White Paper 6. Challenges. Opportunities. Threats

\section{Introduction}

In South Africa, the definition of inclusive education is broadly circumscribed by six affirmations that: all children and youths can learn and need support; there should be relevant structures, systems and methodologies which enable such support in the education system; learners are different and the differences should be respected; learning does not only take place in the formal school but also in the home and the community; changes have to be made to attitudes, behaviour, teaching methods, curricular and the environment in order to meet the learning needs of all learners and that all such efforts are aimed at minimizing barriers to learning while maximizing the participation of all learners in the curriculum and culture of their educational institutions (Department of Education, 2001, p. 6). Thus, it is a more democratic way of understanding values and forming beliefs which welcome and cherish in human diversity (Swart \& Pettipher, 2005, p. 8).

In Zimbabwe inclusive education focuses on all efforts aimed at identifying, reducing or eliminating barriers to students' participation in learning in the context of their homes, communities, and nearest schools such that these societal institutions participate actively in the education process (Mutepfa, Mpofu \& Chataika, 2007, p. 1). In both cases, inclusive education is not just a set of 'cut and dried' practices, but a way of life immersed in a growing national and international democratic conscience.

Definitions of inclusive education vary remarkably, but their major theme is on optimum learner support within the learner's most natural/traditional or typical setting. In the United States the term "least restrictive environment" has been used since 1975 to encompass the diverse concept of inclusion. In the Individuals with Disabilities Education Act (IDEA) of 1975, optimum learner support in a typical classroom entails effective communication and shared responsibilities among members of the Individualised Education Programme (IEP) team (Learning Disabilities Association of America 2012, p. 2). The same idea is the gist of the United Kingdom's Code of Practice of 1994 and 2001 (Code of Practice, 2001). In the latter case, special needs assistants were considered a needful part of a regular classroom with students with special educational needs. The partnership of children who can express their opinions, parents and other agencies is considered prime for inclusive education (Code of Practice 2001, p. 17). The author of this article totally agrees that this is a period of the inclusive education philosophy which should translate into an era of universal inclusive societal practices.

The provision of education for students experiencing barriers to learning, including those who are blind across the 
globe, has undergone tremendous change from the medical model to the social critical model. An expectation that society should play its part in making environments accessible for all has led not only to the adoption of building plans that conform with standards of universal access to the built environment, but to the accommodation of all students in their traditional settings (i.e., schools nearest to their homes) as well (Mutepfa, Mpofu \& Chataika, 2007, p. 1). The motive force gathered by the U N Standard Rules of Action Concerning Persons with Disabilities of 1993, the Salamanca Conference on Special Education of 1994, and the Jomtien Conference on education for all (EFA) of 1990 and more recent international empowerment initiatives has impelled many governments and the scholarly fraternity to proclaim the benefits of inclusive education openly.

South Africa is not an exception to these developments either. Since the advent of democracy in 1994, the country has responded positively to global efforts that seek to empower persons with disabilities and other groups of people who experience various barriers to fulfillment. The point of departure in this article is whether the necessary change has unfolded at a scale big enough to be common knowledge and at a pace fast enough to be ordinarily noticed. It is of cardinal importance to inspect that dimension since the introduction of a new programme comes with the emergence of strong proponents and those who are reluctant or even unprepared to steer the programme to success (University of South Africa, 2006, p. 26). To remove barriers and improve chances for participation of all people in education, inclusive education should not remain as a legislative process alone. It should be an ongoing process which encompasses organisational change (University of South Africa, 2006, p. 26). In South Africa, matters of inclusive education are set in a rights-based context (University of South Africa, 2006, p. 27). Arguing from the rights-based context, any substantial delays in implementing inclusive education would be tantamount to the subjugation of the rights of all students who could have had a stake in the much heralded benefits of inclusive education.

The co-ordination of providing for and supporting students who experience barriers to learning within the context of mainstream schools has been problematic, at least since the 1960s (Crowther, Dyson \& Millward 2001, p. 85). This is despite notions from literature suggesting that inclusive education is easier implemented when inclusive practice is a whole-school initiative (Crowther, Dyson \& Millward, 2001, p. 86; Pijl \& Van Den Bos 2001, p. 112). Further, research in the United Kingdom indicates that it is difficult to start up teacher support programmes (such as those necessary in inclusive education) since schools have difficulties with implementing large-scale external initiatives (Creese, Norwich \& Daniels 2000, p. 321). In that research, only 21 percent of the schools in which the research was conducted were practicing some form of teacher support system or the other. As schools fail to take up programmes that respect the uniqueness of every student, the neglect of 'educationally relevant differences between pupils' is still witnessed (Pijl \& Van Den Bos 2001, p. 113).

The literature explored above exposes two main themes: that inclusive education is agreeably the way forward in this day and age, and that inclusive education policies are easier to put in place than the volition of school personnel to implement them even in the developed world. The extent to which national policies and practices on inclusive education are known to teachers (who should implement them) could be a barometer on the actions that policy-makers and implementers need to take in order for service recipients to benefit from inclusive education programmes.

\subsection{Goals of the Study}

Below, are the goals of the study:

To investigate whether the implementation of policies around inclusion are noticeable to teachers and students, its major end-user stakeholders. The researcher believes that people willingly participate in causes they understand reasonably well. Such participation could include talking positively about the programme in the public domain. Secondly, the study sought to explore both teachers and blind students' understanding of the concept of inclusive education bearing in mind that Education White Paper 6 on inclusive education was officially endorsed in 2001 and would perhaps be expected to be common knowledge to both teachers and blind students, in its eleventh year of enforcement. Finally, the study sought to investigate whether teachers and students at residential secondary schools for the blind saw remarkable progress in the development of inclusive education.

Questions listed below played an instrumental role in soliciting answers and relevant information to the study:

Since the inception of inclusive education in 2001, is there noticeable progress? As an individual, do you know someone at an inclusive school? What are some benefits of inclusive education? What are some challenges to the implementation of inclusive education in South Africa? What are your fears with regards to the inclusive education programme in South Africa? 


\section{Methodology}

\subsection{Design}

The qualitative research design was used in this research. Qualitative research aims more on 'depth validity' rather than 'generalizability' (David \& Sutton 2004, p. 35) in its description of the state of prevailing phenomena. Qualitative research conducted through interviews offers the benefit of gathering information on lived experiences. It also gives the researcher good control over the process of responding to questions (Welman, Kruger \& Mitchell 2005, p. 164). The research is conducted following grounded theory, which is a qualitative research process which generates theories out of the data that it engages (Hamilton 2011, p. 11; McMillan \& Schumacher 2010, p. 346).

\subsection{Sample}

A sample of six teachers (four male and two female); and eighty-three blind students, of whom forty-four were boys and thirty-nine were girls was used. The teachers belonged to the six special schools attended by blind students involved in this research.

\subsection{Instruments}

Data was collected using a semi-structured interview guides. Interview guides are survey instruments. They are therefore appropriate tools for gathering opinions of people (McMillan \& Schumacher 2010, p. 355). Questions used in the interviews were generated following the grounded theory (McMillan \& Schumacher 2010, p. 346). Interview guides enabled the researcher to use the same themes and questions with teachers and students.

\subsection{Data Collection}

The article is informed by the views expressed by practicing teachers from six of thirteen schools for the blind offering grade twelve, and by the views of eighty-three students who attended the 25 to 29 June 2012 winter school at Filadelfia Secondary School in Pretoria. The researcher used seven focus groups to gather information from students (six groups of twelve and one group of eleven). Teachers were interviewed individually. The inclusive-education-literacy levels of both the teachers and the students were considered in the process of formulating questions and interpreting responses, most notably on responses made by students.

\subsection{Data Analysis}

Data was presented in thematic sections which arose from responses made to interviews. The data was then qualitatively examined for meaning. The views of teachers serving at the six schools for the blind and their blind students were sought on the visibility, benefits and challenges of inclusive education initiatives in South Africa since 2001. The responses of teachers and blind students were hermeneutically interpreted in reference to documented national policies and published international developments in inclusive education, in the light of grounded theory and social ecological models (Swart \& Pettipher, 2005, p. 6) applied to education.

\subsection{Ethical Issues}

The permission for teachers and students with visual impairments to take part in the research was granted by the individuals who participated through voluntary participation. All participants were free not to participate, to withdraw at any time without reprisals, and not to answer questions they felt uncomfortable about. Participants were also assured of the confidentiality with which the inputs would be handled, and their anonymity in the whole research process. It was also made known to the participants that data was collected only for the purposes of the present study as described.

\section{Results}

Education White Paper 6 was the main affirmative policy tool backed by the South African Schools Act of 1996 and later assessment policies which confirmed a singular national orientation towards the provision of education to all students, in 
the context of their most inclusive settings.

Students had no linkages whatsoever with the situation before 2001 but said that the term 'inclusive education' was familiar to them. They heard teachers talking about inclusive education from time-to-time.

\title{
3.1 As an individual, do you know someone at an inclusive school?
}

It emerged from the study that two teachers knew one full-service school each, where blind children had been accepted and provisions were made to accommodate their learning needs. Their inputs are quoted below:

\begin{abstract}
In 2010 Bhaqa Primary School in Zululand enrolled a 10 year old blind girl and a 13 year old blind boy. Kwazulu-Natal Blind and Deaf Society and Vryheid District Education Office made the inclusive effort a success. They procured equipment to accommodate the children from the South African National Council for the Blind (Teacher Respondent 1).
\end{abstract}

Glenstentia School in Pretoria accepted a blind girl in January 2012. I have a friend who teaches at the school and she told me that they work hand in hand with the DBE and co-operating partners in the NGO sector, for them to cater for the educational needs of the student (Teacher Respondent 2).

The two inputs cited above are also well known to the researcher. Learners did not have examples of blind children who were attending at full-service schools with the necessary accommodations made to their learning environment.

\subsection{What are some benefits of inclusive education?}

According to teachers, the benefits of inclusive education included but were not limited to the following: preparing students for later life in an inclusive society, establishment of meaningful interaction and friendships, an increase in the number and type of resources available to every student and better appreciation (and acceptance) of differences between individuals, higher expectations for achievement and greater educational outcomes - and respect for all people. Two teachers felt that familiarity with differences did not always bring about acceptance of blind students. The following quote support these findings:

You see, mere familiarity with blind persons does not in itself improve attitudes. A lot has to be done by the school guidance counsellor in terms of advocacy for change. Other advantages exist, like increased social initiations and possibly networks (Teacher Respondent 3).

Students on the other hand were of the view that inclusion facilitated the integration of students with disabilities into their parent communities. They also felt that whatever resources were available to regular school children - and to them as the blind - would be available to all students for common good. Students also articulated the value of their participation in their communities and the importance of cementing friendships within their home communities. The views of learners are captured in the following quotation from one learner:

One is never divorced from one's people. You experience community matters and you are part of the solutions to community problems and challenges. You can also get close friends in your own community, and enjoy your spare time.

\subsection{What are some challenges to the implementation of inclusive education in South Africa?}

Teachers explained that the translation of policies into practice always came with the need for the reallocation of resources for staff training and mass procurement of material resources. It also came with the identification of learners who would be serviced from their least restrictive environments. The fact that parents had a right to choose a school for their child meant that those who did not trust the inclusive route would still opt for their traditional 'Schools for the Blind'. The challenges would be in the area of gathering adequate financial resources for community sensitization, staff training, procurement of physical resources and ongoing staff development. One teacher stated:

For me the challenges would be getting enough teachers to accommodate students with varying educational needs and disabilities. I do not know how a student who needs augmentative and alternative communication and another who uses braille or sign language would be accommodated in the same class. Furthermore, resources are always a problem even in special schools. I am at a loss as to whether there would be enough resources for all children, wherever they attend. As an example, during physical education blind students may feel isolated as they may not have anyone to adapt 
games for them. Where other children would be playing the usual soccer ball, it might not be amusing for one blind student to play a sound ball alone (Teacher Respondent 6).

Students envisaged that challenges would be found around the supply of necessary resources for the education of blind students, walking distances between home and school, possible negative attitudes among some teachers and students and possible lack of requisite support.

A student articulated her feelings thus:

If you do not get the necessary equipment and software, adequately trained educators, an adapted physical learning environment and social set-up, that could be a challenge for a learner.

Another student noted:

If the school is at some distance from my home, I might be late for school while navigating the route alone. Another challenge could be that your presence may not change the negative mindset of some teachers and learners - you see. You will always feel unwelcome in different ways - you see!

A third dimension was brought in by another student:

If learners would not find support in the true and strictest sense of the word, inclusive schooling would be a nightmare. All teachers would need to understand and accept that we also belong there, and our needs should be catered for. I just can't believe that learners would be given material in a format they would be able to read, the right equipment; trained teachers - and that classmates would be willing to go out of their way and offer the much needed support.

\subsection{What are your fears with regards to the implementation of the inclusive education programme in South Africa?}

Teachers agreed that there were so few specialist teachers for students with disabilities (concentrated in special schools) that it would take some years before children in full-service schools could get adequate support from knowledgeable personnel. Responses made by teachers are exemplified through the following quote:

My worry is that there might not be enough knowledgeable teachers to do the work in inclusive schools (Teacher respondent 5).

Students feared factors such as teasing by sighted students, lack of adequately trained teachers, lack of accessible material and 'inclusive isolation' (being ignored within an inclusive school). The general feeling among learners was summarised by one learner who said:

I am afraid that there will be many learners who are blind who will have no friends in those schools. They will be lonely, and included.

\section{Discussion}

\subsection{Since the inception of inclusive education in 2001 , is there noticeable progress?}

The study revealed that change had taken place in terms of the establishment of enabling policies; yet practical implementation was 'remarkably slow'. Education White Paper 6 was the main affirmative policy tool but, the South African Schools Act of 1996 and later assessment policies confirmed a singular national orientation towards the provision of education to all students in the context of their most inclusive setting. This view is shared by Swart \& Petipher (2005, p. 15), who confirm that South African education has 'undergone numerous and radical changes' in the last ten years.

The study also showed that some teachers had received in-service training after the inception of Education White Paper 6. The training was on screening, identification, assessment and support. It also emerged that if there is proper training for teachers on multi-stage teaching, if there is good time management in schools and appropriate mechanisms for multi-disciplinary co-operation - then inclusion would be an attainable reality.

The study also revealed that since support structures such as institution-based and district-based support teams are already in place for inclusive education, what remained was countrywide implementation. It was considered to be rather slow, but happening. It further emerged from the study that learners had no memory of the schooling environment 
prior to 2001. Arguably, they were too young to have remembered anything about school systems during those years, yet some still believed that special schools would be their better option, if they had a choice.

It also emerged from the study that the factors which teachers pointed out as ideal for successful inclusive education were part of what Crowther, Dyson \& Millward, (2001, p. 86) pointed out as 'particular difficulties and challenges that were met by Special Needs Coordinators' in the United Kingdom. The researcher is aware of the students' frustration, and that students in special schools have limited exposure to developments in inclusive education. Inclusive education is firstly a process of reconceptualising values and beliefs so that the concept of diversity is cherished by all (Swart \& Petipher, 2005, p. 8). Following that philosophical persuasion, it is the researcher's view that societal resources should be used for the good of all students.

It also emerged from the study that some schools in South Africa were already practicing inclusive education, but a comprehensive list had to be drawn and widely publicized so that many neighbouring and distant schools would find examples to follow. The role of school principals in both implementation and publicity seems to be quite significant. This finding confirms the observation made by Eyo, Joshua and Esuong, $(2010$, p. 90$)$, that school principals can thwart new programmes if they have little knowledge and conviction about them. This could be the case with the inclusive drive which, despite much publicity since 2001, is still barely visible in many schools. Of essence in this regard is the idea that the inclusive education agenda needs the volition of school principals for it to be visible. The willingness of teachers is also a prerequisite for successful implementation (Pijl \& Van Den Bos 2001, p. 113).

It also emerged from the study that many learners with visual impairments who were in regular schools were there, more by default than by deliberate inclusion. Misdiagnosis of visual conditions could be the main reason for that placement, not learner choice. The author of this article notes the possibility of misdiagnosis as a reality since many teachers do not have a component of special needs education in their initial teacher training. Besides, as noted by Crowther, Dyson \& Millward (2001, p. 180), many inclusive schools do not maintain a register of students with Special Educational Needs (SEN). Such a register is important though, because it could reflect the range of special educational needs of all students in a particular school - and the number of students with such special educational needs (presented as a percentage of the total school enrolment). That record therefore enables the school to plan its staffing function with the teaching load in mind. There is also a tendency for parents and teachers to regard students with low vision as fully sighted and those who are blind as totally blind without light perception (Dickerson, Smith and Moore, 1997, p. 8). Apparently, this leaves many students receiving education without the necessary barrier-specific support.

The study further revealed that inclusive education helped children by preparing them for later life in an inclusive society, the establishment of meaningful friendships, an increase in the number and type of resources available to every student and better appreciation (and acceptance) of differences between individuals. It also emerged that a lot of effort had to be put into the inclusive education process since mere familiarity with blind persons did not in itself improve attitudes. A lot had to be done by the school guidance counsellor in terms of advocacy for change. The school had to evolve through establishing and adhering to policies which teachers, administrative staff and students had to uphold.

The study also revealed that inclusion fostered the integration of students with disabilities into their parent societies earlier in life and that inclusion ensured equal opportunities for all students (to use resources available in the school and the community) if all ideal resources were put together for the benefit of all students.

Although the study also captured a lone and skeptical notion (from a teacher participant) that attitudes do not change, research shows (Chireshe 2011, p. 106) that in some cases long-serving teachers in programmes related to counselling sometimes suffered from burnout and had more negative attitudes towards those programmes than new teachers. In like manner, familiarity with blind students may not necessarily produce positive attitudes towards them in inclusive schools.

The study also revealed that the most important way of translating of policies into practice always was to reallocate resources for staff training and mass procurement of material resources. It was also necessary to move on to the identification of learners who could be serviced from their least restrictive environments. The fact that parents have a right to choose a school for their child means that those who do not trust the inclusive route could still opt for their traditional 'Schools for the Blind'. The challenges come in the way of summoning adequate financial resources for community sensitization, staff training, procurement of physical resources and ongoing staff development.

It also emerged from the study that it was difficult for the country to get enough knowledgeable teachers to man the inclusive education drive in the short run. It was difficult to off-set the need for training because it would possibly take some time to train enough teachers for the whole country. Furthermore, it emerged that resources were a problem even in special schools, and there was a high likelihood that they would be even scarcer when meant for a nation-wide project, taking place in almost every school. As an example, during physical education blind students may feel isolated as they may not have anyone to adapt games for them. Where other children would be playing the usual soccer ball, it might not 
be amusing for one blind student to play a sound ball alone.

As discussed above, teachers involved in this research only raised concerns about overwhelming staff shortages and the diversity of students. However, the Minister of Education who introduced Education White Paper 6 in July 2001 saw five challenges related to teaching, costs, communication, stereotyping and safety of learners (Department of Education 2001, p. 3). The challenges discussed by teachers and students on this question mainly require the allocation of adequate resources and the sensitisation of the entire school community about their various roles in an inclusive educational context. As observed by Croft $(2010$, p. 2), "...states should ensure that 'reasonable accommodation of the individual's requirements is provided'." This could imply training teachers and other professionals in both communication media such as braille - and giving them awareness on matters pertaining to disability in general (United Nations, 2006, p. 17).

It also emerged from the study that basing on projections made in Education White Paper 6 to the present day, that approximately 280000 young persons with disabilities were deemed to be out of school in 2001 (Department of Education, 2001, p. 22), [current figures are projected at 500 000] there was obvious need for urgent implementation of inclusive education but that would come with an 'implementation crisis'. The 6000 students who have various disabilities who were in regular schools currently were just a paltry 1.54\% of the 390000 (average) who were out of the school system. There would be need for a massive resource procurement drive. These findings reveal that government still has a lot to do in its bid to educate all learners with disabilities who are out of school.

It emerged from the study that at the present moment, parents still chose special schools as their preferred school system for children with disabilities, but the author of this article notes that it is usually the case that if there are policy weaknesses, retrogressive implementers find the gaps and use them to stall programmes. The South African Schools Act of 1996, though part of the legal documents that paved way for inclusive education, had some weak areas which were later closed up by the White Paper on an Integrated National Disability Strategy (1997), the National Commission on Special Educational Needs and Training (1997), the National Committee on Education Support Services (1997) and the Education White Paper 6: Special Needs Education: building an inclusive education and training system (2001) (Swart \& Petipher 2005, p. 16). Perhaps after that aggressive spell of policy framing, there should also come an equally aggressive period of effecting wide-spread practice.

It further emerged from the study that in the period before enough teachers are trained for the inclusive school system, teachers in inclusive schools would not likely be in possession of relevant specialist skills in orientation and mobility, making tactile material, writing and reading braille and handling inclusive teaching methods. That would mean a compromise on the quality of education majority of learners, at least for some years.

\section{Recommendations}

On the basis of the findings of the study, it is recommended that all stakeholders join hands and make a bold step towards the whole-hearted implementation of the policies which have been established to-date. Volition seems to be the missing link in the South African Inclusive Education Agenda.

\section{Conclusion}

Problems such as unpreparedness by educators to accommodate students with disabilities, lack of assistive devices, lack of accessible learning teaching support materials, infrastructural barriers, lack of active and passionate institution based learning support teams and district based support teams, inappropriate funding mechanisms, lack of government support and lack of proper inclusive education legislations have been cited by respondents as factors hampering the inclusive education implementation process. The National Department of Education has a mandate to revise the inclusive education implementation time-frames. There is also an urgent need for addressing concerns raised by respondents who participated in this research.

\section{References}

Chireshe R. 2011. School Counsellors' and Students' Perceptions of the Benefits of School Guidance and Councelling Services in Zimbabwean Secondary Schools. Journal of Social Science. 29(2): 101-108.

Creese A, Norwich B, Daniels H 2000. Evaluating Teacher Support Teams in Secondary Schools: Supporting Teachers for SNE and Other Needs. Research Papers in Education. 15(3): 307-324.

Croft A 2010. Including Disabled Children in Learning: Challenges in developing Countries. Brighton: Consortium for Research on 
Educational Access, Transitions \& Equity (CREATE).

Crowther D, Dyson A, Millward, A 2001. Supporting Pupils with Special Educational Needs: Issues and Dilemmas for Special Needs Coordinators in English Primary Schools. European Journal of Special Needs Education. 16(2): 85-97.

David M, Sutton CD 2004. Social Research. The Basics. London: Sage Publishers.

Department of Education. 2001. Education White Paper 6. Special Needs Education: building an inclusive education and training system. Pretoria: Department of Education.

Department for Education and Skills. 2001. Special Educational Needs Code of Practice: LEAs Head Teachers and Governors of Schools, early education practitioners and other Interested Parties. Ref: DfES/581/2001. London: United Kingdom. Available online at: https:www.education.gov.uk/.../DfES\%200581\%20200MIG2228.p...

Dickerson LR, Smith PB, Moore JE 1997. An Overview of Blindness and Visual Impairments. In J.E. Moore, W.H. Graves and J.B. Patterson (Eds), Foundations of Rehabilitation Counseling with Persons Who are Blind or Visually Impaired. New York: American Foundation for the Blind, pp. 1 - 24.

Eyo MB, Joshua AM, Esuong AE 2010. Attitude of Secondary School Students Towards Guidance and Counselling Services in Cross River State. Edo Journal of Counselling. 3(1): 87-99.

Hamilton AB 2011. What is Grounded Theory, Anywhere? An Overview with Examples from Qualitative Research on Women Veterans. VA HSR\&D Cyberseminar. VA: Women's Health Research Network.

Learning Disabilities Association of America 2012. Principles of IDEA. Available online at: http://www.Idanatl.org/aboutld/parents/ special_ed/principles.asp Retrieved on 15 October 2012.

McMillan JH, Schumacher S 2010. Research in Education: Evidence Based Inquiry (7th Ed). Boston: Pearson.

Mutepfa MM, Mpofu E, Chataika T 2007. Inclusive Education in Zimbabwe: policy, curriculum, practice, family, and teacher education issues. Childhood Education. August.

Pijl SJ, Van Den Bos K 2001. Redesigning Regular Education Support in The Netherlands. European Journal of Special Needs Education. 16(2): 111-119.

Swart E, Pettipher R 2005. A Framework for Understanding Inclusion. In: E Landsberg, D Kruger, N Nel. (Eds): Addressing Barriers to Learning: A South African Perspective. Pretoria: Van Schaik Publishers, pp 3-23.

University of South Africa. (2006). Quality Education for All. (Only Reader for HBEd IE-6). Pretoria: University of South Africa.

Welman C, Kruger F, Mitchell B (2005). Research Methodology (3rd Ed). Cape Town: Oxford University Press Southern Africa.

\section{Appendix I}

Table 1: Different respondents

A sample of six teachers (four male and two female); and eighty-three learners of whom forty-four were boys and thirty-nine were girls was used.

\begin{tabular}{|l|c|c|c|}
\hline Teachers & Male & Female & Total \\
\hline & 4 & 2 & 6 \\
\hline Students & Male & Female & Total \\
\hline & 44 & 39 & 83 \\
\hline G/Totals & 48 & 41 & 89 \\
\hline
\end{tabular}

